\title{
Correspondence
}

\section{President's response to editorial by John Cox \& Alison Gray}

I have been asked to comment on the editorial in this edition of the Psychiatric Bulletin. ${ }^{\dagger}$

Beyond politics, beyond factions. Just try a little intelligent kindness - after all this is about putting patients first. To put patients first, professionals themselves have to be valued and supported.

Sue Bailey, immediate past President, Royal College of Psychiatrists doi: $10.1192 /$ pb.38.4.195

To view a sample chapter from Intelligent Kindness: Reforming the Culture of Healthcare by J. Ballatt and P. Campling, visit the College website: www.rcpsych.ac.uk/files/samplechapter/ IntelligentKindnessSC.pdf

\section{Overselling risk assessment}

I need to congratulate Roychowdhury \& Adshead ${ }^{1}$ on a thought-provoking critique. Their arguments struck a chord in exposing the flaws in risk assessment tools and their unjust application in preventative detention; however, I was disappointed that they did not go further. All of these tools, structured clinical judgement included, apply populationderived data to individuals, thus painting them with the behaviour of their peers. The central flaw of risk assessment lies in presuming causality from association. The premise in these tools that symptom severity invariably correlates with risk is demonstrably fallacious, as any psychiatrist could counter-cite cases where treating the mental illness improves functional ability in patients who choose pro-criminal lifestyles.

The second problem, as previously highlighted by Szmukler, ${ }^{2}$ is their inherent determinism by casting the subject (participant) as a hapless automaton. Society is rightly critical of the boorish youth who binge drinks and gets into fights, yet exculpates the capacitous non-adherent person with schizophrenia - and holds their psychiatrist vicariously liable for their violence.

Risk assessment attempts to sanitise an unpalatable fact that violence is part of the human condition, which exists independently of mental illness. Milgram ${ }^{3}$ and Zimbardo ${ }^{4}$ infamously illustrated this. Nonetheless, even when convicted, the offender without a mental disorder rarely faces the sanction of possible indefinite detention. Indeed, it was implicit in the debate around dangerous and severe personality disorder and the 2007 revisions to the Mental Health Act that psychiatry could be manipulated into preventatively detaining risky individuals in society without the bothersome need for a trial. $^{5}$

The truth is that risk assessment has become an industry. Those devising the next 'marginally-better-than-chance' tool can live off the proceeds of the copyright, training seminars and subsequent release of version 2.0. It is also politically

†See editorial, pp. 152-153, this issue. expedient in reverse-engineering a scapegoat and providing glib platitudes that 'lessons are learnt', and 'something is done' in a world increasingly tilting at the reality of rare unpleasant events.

I believe that expectation regarding the prescience of risk assessment has far outstripped the reality of what it can achieve. The evidence base for risk assessment, by the authors' own conclusion, would not support its use as a diagnostic instrument; yet in clinical practice it is insidiously taking over as a priority. Criminal justice operates on the principle that it is better to let ten guilty men go free than convict one innocent. If the original question was one of ethics, surely for an exception to be made for those with a mental illness is frankly discriminatory.

Furthermore, the question around the ethical principle of beneficence remains unanswered: if risk assessment is a priority activity, what is the evidence that it improves clinical outcomes over and above quality standard care? I cannot offer an alternative other than to lament the fact that the Richardson Committee's report in 1999 on transforming mental health legislation from risk- to capacity-based was never realised. We need to refocus this debate clinically by emphasising 'needs assessment' over 'risk assessment'. Risks are unavoidable; but good-quality evidence-based care should not be usurped by the latest fashionable risk assessment tool.

1 Roychowdhury A, Adshead G. Violence risk assessment as a medical intervention: ethical tensions. Psychiatr Bull 2014; 38: 75-82.

2 Szmukler G. Homicide inquiries: what sense do they make? Psychiatr Bull 2000; 24: 6-10.

3 Milgram S. Behavioural study of obedience. J Abnorm Soc Psychol 1963; 67: 371-8.

4 Zimbardo PG. The Power and Pathology of Imprisonment. Congressional Record (Serial No. 15, 1971-10-25). Hearings before Subcommittee No. 3, of the Committee on the Judiciary, House of Representatives, NinetySecond Congress, First Session on Corrections, Part II, Prisons, Prison Reform and Prisoner's Rights: California. U.S. Government Printing Office, 1971.

5 Per Jack Straw, then Home Secretary. Hansard (HC) 1999; 15 February: col 601-3.

Trevor D. Broughton, consultant forensic psychiatrist, Norvic Clinic, Norwich, email: trevor.broughton@nsft.nhs.uk

doi: $10.1192 / p b .38 .4 .195 a$

\section{GMC guidance needed}

Roychowdhury \& Adshead should be thanked for raising the issue of the ethics of the use of actuarial risk assessment in psychiatry. ${ }^{1}$ These ethics might at first appear obvious: medical practitioners must have an overriding duty to protect the public from serious crime. It follows that they must do everything possible to accurately assess the risk of such crime, including the use of these assessment instruments. However, as Roychowdhury \& Adshead point out, these instruments will produce misleading results if the prevalence of the serious crime being considered in the relevant population is low or unknown. Indeed, they point out: 'A key challenge in psychiatry is that base rates [of the prevalence of serious crime] are often 
not known, are low and vary for different types of violence.' So if doctors use these assessments they risk wrongly identifying their patient as at high risk of committing a serious crime, and then act in a way that is not in the best interests of that patient. Such an act would of course be inconsistent with the duties of a doctor as set out by the General Medical Council (GMC) in Good Medical Practice. ${ }^{2}$ It follows that while the prevalence of particular serious crimes in various patient populations is unknown or is known to be low, the use of these actuarial risk assessments will remain unethical. As Roychowdhury \& Ashhead conclude: '[structured professional judgement] tools used as checklists of risk factors without construction of risk scenarios or a risk management plan remains harmful and unethical practice.' In my opinion psychiatrists would value guidance on this issue from the GMC.

1 Roychowdhury A, Adshead G. Violence risk assessment as a medical intervention: ethical tensions. Psychiatr Bull 2014; 38: 75-82.

2 General Medical Council. Good Medical Practice. GMC, 2013.

Keith E. Dudleston, consultant psychiatrist (retired), Ivybridge, UK, email: dudleston@btinternet.com

doi: $10.1192 / p b .38 .4 .195 b$

\section{Risk assessment and evidence-based medicine}

The article by Roychowdhury \& Adshead starts to place violence risk assessment in the context of medical care. Although this is welcome, their partial defence of risk assessment in general, and of structured professional judgement in particular, is based on some significant distortions.

The first distortion is the gross overestimation of the power of risk assessment to discriminate between low-risk and high-risk people. The authors present a contingency table that they imagine shows the 'potential' outcomes of a violence risk assessment (Table 2). Using their tabulated data, a diagnostic odds ratio for risk assessment can be calculated to be 81 , indicating that the risk of violence in the high-risk group (50\%) is hugely higher than in the low-risk group (1.2\%). These figures are totally unrealistic. In fact, the diagnostic odds ratio of violence risk assessment in replication studies was recently estimated by meta-analysis ${ }^{2}$ to be 3 . Roychowdhury \& Adshead overestimate the discriminating power of risk assessment by 27 times. Moreover, even an unrealistically powerful risk assessment with diagnostic odds of 16 is of little or no value because of failure to detect potential violence in the low-risk group and the large proportion of false positives in the high-risk group. ${ }^{3}$

The second distortion relates to the underestimation of the precision of medical tests. In fact, the authors seem to have had difficulty finding any medical test with diagnostic odds that they could compare to a violence risk assessment. Instead they chose to compare two medical treatments. They argue that the high number-needed-to-treat as a result of a violence risk assessment is acceptable in psychiatry because in cardiology the number of bypass grafts needed to prevent one fatal outcome has been calculated to be $53 .{ }^{3}$ However, the meta-analysis they derived this figure from compared coronary bypass surgery to angioplasty - both of which are highly efficacious treatments for angina. ${ }^{3}$ In reality, medical tests that are used to diagnose conditions with serious implications for the patient are very accurate - biopsy is an excellent indicator of cancer and an angiogram a good indicator of coronary heart disease.

Despite these limitations, I support the authors' general idea of viewing risk assessment as a medical procedure. I would go further: surely violence risk assessment should be judged by the standards of evidence-based medicine. The real questions then become: (1) are there any rational interventions that can be justified in terms of cost and benefit that might reduce violence among high-risk patients (many of whom will not be violent) and yet should not be offered to low-risk patients (who commit as many or even the majority of acts of violence); and (2) is there evidence that shifting treatment resources from low-risk to high-risk people can, in any way, reduce overall levels of harm?

The answer to both these questions is no. ${ }^{4,5}$ There is no doubt that medical diagnostic tests serve as a good basis for medical treatment and that medical and surgical treatment can save lives. It is simply disingenuous to suggest that the same can be said of violence risk assessment.

Declaration of interest: M.L. has provided expert evidence in matters relating to risk assessment.

1 Roychowdhury A, Adshead G. Violence risk assessment as a medical intervention: ethical tensions. Psychiatr Bull 2014; 38: 75-82.

2 Singh JP, Grann M, Fazel S. Authorship bias in violence risk assessment? A systematic review and meta-analysis. PLoS One 2013; 8: e72484.

3 Hoffman SN, TenBrook JA, Wolf MP, Pauker SG, Salem DN, Wong JB. A meta-analysis of randomized controlled trials comparing coronary artery bypass graft with percutaneous transluminal coronary angioplasty: one- to eight-year outcomes. J Am Coll Cardiol 2003; 41: 1293-304.

4 Large MM, Ryan CJ, Callaghan S, Paton MB, Singh SP. Can violence risk assessment really assist in clinical decision-making? Aust N Z J Psychiatry 2014; 48: 286-8.

5 Wand T, Large M. Little evidence for the usefulness of violence risk assessment. Br J Psychiatry 2013; 202: 468.

Matthew Large, psychiatrist, School of Psychiatry, University of New South Wales, Sydney, Australia, email: mmbl@bigpond.com.

doi: $10.1192 / p b .38 .4 .196$

Author response: We thank Dr Matthew Large for his helpful comments. We wished to respond only by clarifying that the figures in Table 2 were from a hypothetical population, based on a hypothetical risk assessment tool with certain sensitivity and specificity values. The purpose was to illustrate that, even in risk assessments with unrealistic accuracy levels, the positive predictive value (PPV) was still low, as it was greatly influenced by the base rate. Any misleading odds ratios arising from the table was not intentional and arose (perhaps ironically) by chance.

Ashimesh Roychowdhury, consultant forensic psychiatrist and associate medical director, St Andrew's Healthcare, Northampton, email: ARoychowdhury@standrew.co.uk, and Gwen Adshead, consultant forensic medical psychotherapist, Broadmoor Hospital, Crowthorne, Berkshire.

doi: $10.1192 / \mathrm{pb} .38 .4 .196 \mathrm{a}$

\section{OCTET Study: flawed by type 2 error}

The OCTET study overcame many legal and ethical difficulties in setting up a randomised controlled trial (RCT) of community treatment orders (CTOs). ${ }^{1}$ We welcome the acknowledgment 